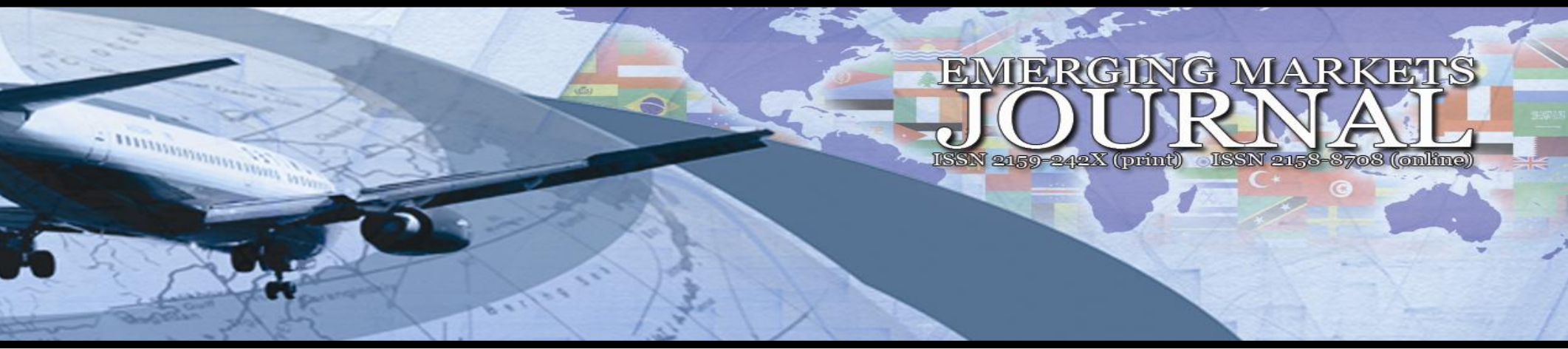

\title{
Volatility Transmission between Dow Jones Stock Index and Emerging Islamic Stock Index: Case of Subprime Financial Crises
}

Amir Saadaoui

Email: $\underline{\text { am.saadaoui@yahoo.fr }}$

\section{Younes Boujelbene}

Email: younes.boujelbene@yahoo.fr

Volume 5 No 1 (2015) ｜ ISSN 2158-8708 (online) | DOI 10.5195/emaj.2015.68 | http://emaj.pitt.edu |

Abstract

In the course of the recent global crisis, the stock shocks are distributed and transmitted from their homes in the developed stock market to emerging stock markets. By supporting the development of emerging stock markets, this study aims to see the transmission of volatility between the Dow Jones stock index and the Dow Jones emerging Islamic stock index. In this study we have divided the period into three, periods, before, during and after this crisis to demonstrate the resilience of the Islamic market index in response to the global financial crisis. Another aim of this study is to provide a new guide line for investors in emerging stock market before making investment decisions. The data are daily, going from 02/01/2005 until 31/12/2012. To measure the transmission we used vicariate BEKK-GARCH and DCC-GARCH model. The result shows that there is a transmission mainly during the crisis period which means that the crisis affects all the financial assets whether Islamic or not. The same result also shows the preference to invest in both Islamic and classical stock indexes since they are less risky.

Keywords: Volatility transmission, DJ Index, Islamic DJ Emerging Index, Subprime crisis $(\mathrm{cc}) \mathrm{BY}$

New articles in this journal are licensed under a Creative Commons Attribution 3.0 United States License.

\section{ULIS D-Sente}

This journal is published by the University Library System of the University of Pittsburgh as part of its D-Scribe Digital Publishing Program, and is cosponsored by the University of Pittsburgh Press. 


\section{Volatility Transmission between Dow Jones Stock Index and Emerging Islamic Stock Index: Case of Subprime Financial Crises}

\author{
Amir Saadaoui \\ Younes Boujelbene
}

\section{Introduction}

The stock market crash around the world during the subprime crisis period demonstrated the financial contagion of the current global financial crisis. Although the subprime crisis first hit real estate markets in the United States, it soon spread all over the world to affect all the emerging markets like Indonesia and other Asian countries in South Est Asia. Ahlgren and Antell (2009), clearly explained that one of the most important features of globalizations and speedy transmission of information across markets is the extend of the financial crisis from, one market to another even if the fundamental economies are different. Therefore, the strong economic ties between emerging and developed markets become the conductor of contagion. Indeed, investors need a guide line to effective investment portfolio, a less risky investment that can withstand the market shocks. In this context, Yang and Qiu (2005), show that the risk is essential in investment from the time when the risk is a factor that shapes the decision of investors to make investments. Therefore, the risk of investment can guide the investor in the development of efficient portfolio, especially during the crisis period.

Due to the rapid development of Islamic finance and investment, this paper attempts to study the transmission of volatility in the Dow Jones Index and in Emerging Islamic Index and in emerging countries. Similarly, to measure the resistance of Islamic market indexes faced in the last financial crisis, we can invest in the Islamic index. This study can be used as a guide for new investors in emerging stock markets, since it shows that Islamic equity indexes are more favorable to create an effective investment portfolio. The study examines the volatility transmission between the stock index and Dow Jones Emerging Islamic country indices Hungary, Malaysia, Mexico, Peru, Poland and Turkey. It also shows the resistance of these indexes when facing the subprime crisis.

This document is divided into five sections covering the above discussion; the first section is the introduction of the research that includes the context and objectives of the study. The next section discusses the literature review. The data and methods of observation are discussed in Section 3, while the result and the empirical analysis will be described and discussed in Section 4. Finally, we end up with a conclusion in which the results are discussed.

\section{Literature Review}

Market growth of the Islamic capital has drawn the attention of many investors worldwide who that Muslims and non-Muslims.

In discussing the situation of Islamic indexes in the financial sphere, Charles, Steak and Pop (2011) found in their study that, during the crisis, Islamic indices were by the subprime crisis affected in the same way as conventional indices. Indeed, when testing the relationship between these indexes relative to other periods, the authors found that the variance was not the same, where as Islamic indexes were slightly higher compared to conventional indices volatility. In the context of risk, Al-Zoubi and Maghyereh (2007) found that Islamic indices are less risky than conventional indices, which brings us back to the principle of sharing profits and losses of Islamic finance. Regarding the correlation between the indices, Rizvi and Arshad (2012) found a weak correlation of movement between conventional and Islamic evidence proving that the Islamic index may provide a better alternative to withstand against the crisis. Several studies (Kumar Mukhopadhyay (2002), Wong, Agarwal and Du (2005) showed that there is a correlation between different markets around the world, which clearly explains the transmission of crises from one market to another. They further emphasized that dramatic movements in one equity market 
can have a powerful impact on different markets. Similarly, for Islamic indexes, Majid, Meera and Omar (2007), Rahman and Sidek (2011); Siskawati, (2011) found that volatility in all the major global markets is unlikely to affect Islamic indices. On the other hand, several other studies showed that there is no empirical co-integration between Islamic indices (Karim Kassim and Arip (2010) and Yusof and Majid (2007)).

\section{DATA AND METHODOLOGY}

\subsection{Data Description}

A part of the empirical study of this research is a multi-step process, where we try to analyze the sequence data from descriptive statistics. The core of our model is to study the transmission of volatility between conventional Dow Jones and Six Islamic indices. All these stock market indices used in the empirical study were taken from the Dow Jones Index family. We consider daily data from DataStream for the various indices between 3 January 2005 and 31 December, 2012. We have sub-divided this period into three periods, Pre- crisis period (January 3, 2005 to Jun 29, 2007) during crisis period (July 03, 2007 to December 31, 2010) and Post crisis period (January 02, 2011 to December $31,2012)$.

These Indexes and their respective indices are as follows: the USA Standard Index, the Dow Jones Index (DJI), for Hungary, Islamic Dow Jones Stock Index of Hungary (DJIIH); for Malaysia (MY), Islamic Dow Jones Index of Malaysia (DJIIMY); for Turkey (TKY), Islamic Dow Jones Index of Turkey (DJIIMTR); for Mexico (MEX), Islamic Dow Jones Index of Mexico (DJIIME); for the Peru, Islamic Dow Jones Index of Peru (DJIIPE); and for Poland, Islamic Dow Jones Index of Poland (DJIIPO).

\subsection{Methodology}

Much attention was paid to the way news from one market can affect the volatility process of another market. In this study, we analyze the mean and volatility spillover effects between the Dow Jones stock conventional Index and Islamic emerging Index using a bivariate framework of the
BEKK parameterization (Engle and Kroner, 1995). In this model, the variance-covariance matrix of equations depends on the squares and cross products of innovation $\varepsilon_{t}$, derived from the following mean equation:

$$
R_{t}=U_{t}+\varepsilon_{t}, \varepsilon_{t} / \Omega_{t-1} \approx N(0, H)
$$

Where $R_{t}$ is the $2 \times 1$ vector of returns at time $t$ for each market. The $n \times 1$ vector of random errors, $\varepsilon_{t}$ represents the innovation for each market at time $t$ with its corresponding $2 \times 2$ conditional variance-covariance matrix $H_{t}$ The market information available at time $t-1$ is represented by $\Omega_{\mathrm{t}-1}$. Thus, we investigate the volatility spillover effect using the BEKK bivariate GARCH model. The standard BEKK parameterization of the bivariate GARCH model is written as

$H_{t}=C^{\prime} C+A^{\prime} \varepsilon_{t-1} \varepsilon_{t-1}^{\prime} A+B^{\prime} H_{t-1} B$,

Where $H_{t}$ is a $2 \times 2$ matrix of conditional variancecovariance at time $t$ and $C$ is a $2 \times 2$ lower triangular matrix with three parameters. $A$ is a $2 \times 2$ square matrix of coefficients that measures the extent to which conditional variances are correlated with past squared errors. $B$ is a $2 \times$ 2 squared matrix of coefficients that shows the extent to which current levels of conditional variances are related to past conditional variances. Thus, we will have:

$\left[\begin{array}{ll}h_{11, t} & h_{12, t} \\ h_{21, t} & h_{22, t}\end{array}\right]=\left[\begin{array}{ll}C_{11} & \\ C_{21} & C_{22}\end{array}\right],\left[\begin{array}{ll}C_{11} & \\ C_{21} & C_{22}\end{array}\right]+$

$\left[\begin{array}{ll}\alpha_{11} & \alpha_{12} \\ \alpha_{21} & \alpha_{22}\end{array}\right],\left[\begin{array}{cc}\varepsilon_{1, t-1}^{2} & \varepsilon_{1, t-1} \varepsilon_{2, t-1} \\ \varepsilon_{2, t-1} \varepsilon_{1, t-1} & \varepsilon_{2, t-1}^{2}\end{array}\right]\left[\begin{array}{ll}\alpha_{11} & \alpha_{12} \\ \alpha_{21} & \alpha_{22}\end{array}\right]+$

$\left[\begin{array}{ll}b_{11} & b_{12} \\ b_{21} & b_{22}\end{array}\right],\left[\begin{array}{ll}h_{11, t-1} & h_{12, t-1} \\ h_{21, t-1} & h_{22, t-1}\end{array}\right]\left[\begin{array}{ll}b_{11} & b_{12} \\ b_{21} & b_{22}\end{array}\right]$,

Where $h_{11, \mathrm{t}}$ denotes the variance in Dow Jones stock index returns, $h_{12, \mathrm{t}}$ the covariance in the Dow Jones stock index returns and Islamic index returns, and $h_{22, \mathrm{t}}$ the variance in Islamic index returns. The significance of the diagonal coefficients $a$ 11,t $\left(a_{22, \mathrm{t}}\right)$ suggests that the current conditional variance of $h_{11, \mathrm{t}}\left(h_{22, \mathrm{t}}\right)$ is correlated with its own past squared errors, while the significance of the lagged variance $b 11, \mathrm{t}(\mathrm{b} 22, t)$ indicates that the current conditional variance of $h_{11, \mathrm{t}}\left(h_{22, \mathrm{t}}\right)$ is affected by its own 
past conditional variance. In addition, the significance of the off-diagonal coefficients $a_{12, \mathrm{t}}$ and $b_{12}$ indicates the evidence of a volatility spillover effect from the Dow Jones stock Index to the Islamic index in the emerging markets, whereas the significance of the off-diagonal coefficients $a_{12}$ and $b_{12}$ suggests the evidence of a volatility spillover effect from the Dow Jones stock Index to the Islamic Index market. The standard BEKK model implies that only the magnitude of past return innovations is important in determining current conditional variances and covariances.

\section{DESCRIPTIVE STATISTICS}

The descriptive statistics for the daily returns of DJ conventional stock index and 6 DJ Islamic market index in the table below. In fact, this study explores important information represented by the standard deviations.

Tables 1. Descriptives statistics of DJ Index and Emerging Islamic Index

\begin{tabular}{|c|c|c|c|c|c|c|c|}
\hline \multicolumn{8}{|c|}{ Index } \\
\hline & DJI & DJHI & DJM & DJM & DJPe & DJPo & DJTI \\
\hline & & $\mathbf{I}$ & aII & eII & II & II & I \\
\hline \multicolumn{8}{|c|}{ Pre-crisis Period (Janury 2, 2005 to Jun 29, 2007) } \\
\hline Mea & 0.000 & 0.001 & 0.001 & 0.002 & 0.001 & 0.001 & 0.001 \\
\hline $\mathbf{n}$ & 628 & 399 & 240 & 014 & 162 & 277 & 410 \\
\hline Std. & 0.008 & 0.019 & 0.009 & 0.017 & 0.024 & 0.021 & 0.023 \\
\hline Dev & 243 & 787 & 906 & 132 & 634 & 064 & 855 \\
\hline Ske & - & 0.595 & 0.687 & 0.338 & 0.483 & 1.076 & - \\
\hline wne & 0.169 & 519 & 466 & 155 & 223 & 851 & 2.641 \\
\hline ss & 089 & & & & & & 548 \\
\hline Kur & 5.088 & 11.08 & 10.55 & 12.63 & 21.34 & 18.74 & 36.25 \\
\hline tosis & 279 & 613 & 099 & 955 & 123 & 935 & 642 \\
\hline Jar & 93.04 & 1388. & 1224. & 1941. & 7013. & 5253. & 2357 \\
\hline que- & $83 * *$ & $969 *$ & $794 *$ & $491 *$ & $750 *$ & $649 *$ & $5.68^{*}$ \\
\hline Ber & $*$ & $* *$ & $* *$ & $* *$ & $* *$ & $* *$ & $* *$ \\
\hline \multicolumn{8}{|l|}{ a } \\
\hline \multicolumn{8}{|c|}{ During the crisis period (Jully 2, 2007 to December 31, 2012) } \\
\hline Mea & - & $3.39 \mathrm{E}$ & 0.000 & 0.000 & 0.000 & - & 0.000 \\
\hline $\mathbf{n}$ & 0.000 & -05 & 267 & 486 & 817 & $9.43 \mathrm{E}$ & 142 \\
\hline & 285 & & & & & -05 & \\
\hline Std. & 0.019 & 0.029 & 0.013 & 0.024 & 0.030 & 0.027 & 0.027 \\
\hline Dev & 472 & 952 & 230 & 863 & 628 & 367 & 296 \\
\hline Ske & 0.285 & 0.413 & - & 0.422 & 0.434 & 0.074 & 0.077 \\
\hline wne & 118 & 618 & 0.498 & 559 & 684 & 346 & 837 \\
\hline ss & & & 800 & & & & \\
\hline Kur & 9.042 & 9.206 & 9.440 & 9.170 & 7.721 & 6.145 & 7.789 \\
\hline tosis & 33 & 964 & 654 & 728 & 582 & 266 & 031 \\
\hline Jar & 1404. & 1494. & 1619. & 1478. & 878.7 & 378.0 & 875.3 \\
\hline que- & $35^{* *}$ & $909 *$ & $444^{*}$ & $949 *$ & $484^{*}$ & $021^{*}$ & $138^{*}$ \\
\hline Ber & $*$ & $* *$ & ** & $* *$ & ** & $* *$ & $* *$ \\
\hline
\end{tabular}

\begin{tabular}{|c|c|c|c|c|c|c|c|}
\hline \multicolumn{8}{|l|}{$\mathbf{a}$} \\
\hline \multicolumn{8}{|c|}{ Post-crisis period ( January 2, 2011 to December 31, 2012) } \\
\hline Mea & $3.67 \mathrm{E}$ & - & 0.000 & 0.000 & 0.001 & $2.80 \mathrm{E}$ & 0.000 \\
\hline \multirow[t]{2}{*}{$\mathbf{n}$} & -05 & 0.000 & 353 & 379 & 892 & -05 & 689 \\
\hline & & 209 & & & & & \\
\hline Std. & 0.016 & 0.022 & 0.008 & 0.017 & 0.048 & 0.020 & 0.019 \\
\hline Dev & 200 & 770 & 893 & 060 & 412 & 383 & 392 \\
\hline Ske & - & 0.160 & - & - & 16.75 & - & 0.114 \\
\hline wne & 0.198 & 296 & 0.369 & 0.110 & 924 & 0.310 & 956 \\
\hline ss & 471 & & 679 & 63 & & 052 & \\
\hline Kur & 4.255 & 4.113 & 4.431 & 4.786 & 348.4 & 5.715 & 4.770 \\
\hline tosis & 589 & 413 & 941 & 105 & 953 & 666 & 469 \\
\hline Jar & 37.64 & 29.14 & 56.37 & 70.31 & 2615 & 168.4 & 69.19 \\
\hline que- & $368^{*}$ & $272 *$ & $878^{*}$ & $614^{*}$ & 647.* & $430^{*}$ & $359 *$ \\
\hline Ber & $* *$ & $* *$ & $* *$ & $* *$ & $* *$ & $* *$ & $* *$ \\
\hline a & & & & & & & \\
\hline
\end{tabular}

Notes: Jarque-Bera corresponds to the test statistic for the null hypothesis of normality in the sample returns distribution. $* * *$ indicates the rejection of the null hypothesis at the $1 \%$ significance level.

The descriptive analysis is used to provide a preliminary description of the nature and volatility indices. At the same time, it helps to compare the performance indicators based indices license, allowing observation of how they stand against each other. Table 1 is summary of the statistics on index returns of Dow Jones standard and some emerging Islamic indices for the periods of, pre-crisis, during crisis and post-crisis. In the pre-crisis period, the Dow Jones conventional Index has low volatility with a low Std. Dev (0.008243) unlike other Islamic indices that are the most active and profitable with the highest Std.Dev (0.024634) for Peru, showing the highest average daily returns of $0.2014 \%$ for Mexico. The other two periods show the same information. For the crisis period, the Dow Jones index standard has low volatility with Std.Dev (0.019472) and a negative average $(-0.000285)$. It is lower than Islamic indexes which are more volatile and have a higher Std.Dev $(0.030628)$ for Peru and the highest $(0.000486)$ average for Mexico. For the post-crisis period all the features are more preferable for Islamic indexes except for Hungary which has a negative average (-0.000209) and Malaysia, which has the lowest Std.Dev (0.008893). 
However, DJ Islamic stock index is highly volatile as it has a significantly higher kurtosis value during the three different periods.

\section{EMPIRICAL RESULTS}

In order to examine the volatility transmission between Dow Jones conventional Index and emerging Dow Jones Islamic Index, we first estimate the BEKK bivariate GARCH $(1,1)$ models. Table 2 reports the results for the averages and variance equations of the GARCH estimations over the pre-, in, and post-2008 crisis periods.

Notes: $* * *$ indicates the level of signification at $1 \%, * *$ at $5 \%$ and $*$ at $10 \%$.
Table 2. Volatility transmission between DJ Standard Index and emerging DJ Islamic Index

\begin{tabular}{|c|c|c|c|c|c|c|}
\hline & DJIIH & $\begin{array}{l}\text { DJIIM } \\
\text { Y }\end{array}$ & $\begin{array}{l}\text { DJII } \\
\text { ME }\end{array}$ & DJIIPE & DJIIPO & DJIITR \\
\hline \multicolumn{7}{|c|}{ Pre-crisis period } \\
\hline$\alpha($ & $(0.0352$ & $(0.0618$ & $(-$ & $(-$ & $(0.3942$ & $(0.00534$ \\
\hline 1 & 64889) & 19471) & 0.0534 & 0.22750 & 16400) & 624) \\
\hline \multirow[t]{3}{*}{ 2) } & 0.79641 & 0.59846 & $650)$ & 577) & 0.02448 & 0.978406 \\
\hline & 784 & 494 & 0.6912 & 0.04781 & $985^{* * *}$ & 82 \\
\hline & & & 4535 & $214 * *$ & & \\
\hline$\alpha($ & $(-$ & $(0.0672$ & $(-$ & $(0.0129$ & $(-$ & $(-$ \\
\hline 2 & 0.02323 & 77971) & 0.0150 & 67414) & 0.06320 & 0.000365 \\
\hline \multirow[t]{3}{*}{ 1) } & 412) & 0.48231 & 554) & 0.31550 & 102) & 5) \\
\hline & 0.22774 & 962 & 0.4604 & 247 & 0.01241 & 0.977065 \\
\hline & 736 & & 2417 & & $957 * *$ & 91 \\
\hline$\beta($ & $(-$ & $(0.1331$ & $(-$ & $(0.0350$ & $(-$ & $(-$ \\
\hline 1 & 0.00277 & $51840)$ & 0.0143 & 92532) & 0.68569 & 0.022454 \\
\hline \multirow[t]{3}{*}{ 2) } & 494) & 0.30465 & 461) & 0.64572 & 148) & 1) \\
\hline & 0.96156 & 732 & 0.7976 & 714 & 0.00027 & 0.748744 \\
\hline & 896 & & 9639 & & $64 * * *$ & 21 \\
\hline$\beta($ & $(0.0081$ & $(-$ & $(-$ & $(-$ & $(0.0572$ & $(-$ \\
\hline 2 & 30994) & 0.21120 & 0.0009 & 0.00610 & 27937) & 0.006171 \\
\hline \multirow[t]{3}{*}{ 1) } & 0.55585 & 443) & 963) & 822) & 0.07730 & 3) \\
\hline & 173 & 0.22327 & 0.9449 & 0.46677 & $393 *$ & 0.506439 \\
\hline & & 80 & 4525 & 779 & & 43 \\
\hline \multicolumn{7}{|c|}{ During crisis period } \\
\hline$\alpha($ & $(-$ & $(0.5176$ & $(0.128$ & $(0.2283$ & $(0.1324$ & $(-$ \\
\hline 1, & 0.04988 & 28634) & 999) & 3934) & 60833) & 0.062037 \\
\hline 2) & 442) & 0.00000 & 0.2704 & 0.05962 & 0.02311 & 238) \\
\hline & $\begin{array}{l}0.36387 \\
246\end{array}$ & $01 * * *$ & 372 & $444 *$ & $598 * *$ & $\begin{array}{l}0.564825 \\
78\end{array}$ \\
\hline$\alpha($ & $(-$ & $(-$ & $(-$ & $(-$ & $(0.0197$ & $(-$ \\
\hline 2 & 0.00722 & 0.03239 & 0.0442 & 0.04522 & 40279) & 0.023228 \\
\hline \multirow[t]{3}{*}{ 1) } & 51) & 434) & 158) & 429) & 0.40214 & $805)$ \\
\hline & 0.58208 & 0.44820 & 0.0407 & 0.00801 & 648 & 0.263948 \\
\hline & 603 & 304 & 7348 & $68 * * *$ & & 24 \\
\hline$\beta($ & $(0.0300$ & $(-$ & $(-$ & $(-$ & $(-$ & $(0.14636$ \\
\hline 1 & 1402) & 0.36347 & 0.0342 & 0.10401 & 0.04769 & 7107) \\
\hline \multirow[t]{3}{*}{ 2) } & 0.15190 & 158) & 235) & 151) & 089) & 0.003556 \\
\hline & 820 & 0.00000 & 0.6729 & 0.25167 & 0.02512 & $85^{* * *}$ \\
\hline & & $00 * * *$ & 2081 & 864 & $441 * *$ & \\
\hline$\beta($ & $(0.0007$ & $(0.1752$ & $(0.012$ & $(0.0135$ & $(-$ & $(0.00115$ \\
\hline 2 & 5246) & 09329) & 36787) & 19372) & 0.00951 & 6709) \\
\hline \multirow[t]{2}{*}{ 1) } & 0.84346 & 0.00025 & 0.1453 & 0.01446 & 448) & 0.887954 \\
\hline & 644 & $99 * * *$ & 1417 & $224 * *$ & $\begin{array}{l}0.27107 \\
089\end{array}$ & 01 \\
\hline \multicolumn{7}{|c|}{ Post-crisis period } \\
\hline$\alpha($ & $(-$ & $(0.0091$ & $(-$ & $(-$ & $(-$ & $(0.09035$ \\
\hline 1 & 0.06145 & 29657) & 0.0106 & 0.00025 & 0.00476 & $8756)$ \\
\hline \multirow[t]{3}{*}{ 2) } & 403) & 0.70802 & 837) & 128) & 613) & 0.285861 \\
\hline & 0.18260 & 122 & 0.7980 & 0.99629 & 0.91265 & 23 \\
\hline & 564 & & 1413 & 830 & 234 & \\
\hline$\alpha($ & $(0.0663$ & $(0.0579$ & $(0.068$ & $(0.0375$ & $(0.0465$ & $(-$ \\
\hline 2 & $81837)$ & 91610) & $74255)$ & 05750) & 52194) & 0.008525 \\
\hline \multirow[t]{2}{*}{ 1) } & 0.00019 & 0.26759 & 0.0139 & 0.28784 & 0.04338 & 597) \\
\hline & $85^{* * *}$ & 740 & 3318 & 447 & $228 * *$ & $\begin{array}{l}0.816129 \\
94\end{array}$ \\
\hline$\beta($ & $(-$ & $(0.0043$ & $(-$ & $(0.0148$ & $(-$ & $(0.01037$ \\
\hline 1 & 0.02538 & 08421) & 0.0109 & 64547) & 0.03013 & 6919) \\
\hline \multirow[t]{3}{*}{ 2) } & 619) & 0.55116 & 995) & 0.42949 & 006) & 0.698290 \\
\hline & 0.08717 & 992 & 0.3549 & 865 & 0.05432 & 98 \\
\hline & $407^{*}$ & & 2183 & & $040 *$ & \\
\hline$\beta($ & $(-$ & $(-$ & $(-$ & $(-$ & $(-$ & $(-$ \\
\hline 2 & 0.01300 & 0.04232 & 0.0223 & 0.00652 & 0.00279 & 0.023163 \\
\hline \multirow[t]{3}{*}{ 1) } & 207) & 759) & 170) & 635) & 763) & 135) \\
\hline & 0.00375 & 0.01470 & 0.0032 & 0.64311 & 0.68769 & 0.418777 \\
\hline & $48^{* * *}$ & $664 * *$ & $59 * * *$ & 734 & 427 & 13 \\
\hline
\end{tabular}

Volatility Transmission between Dow Jones Stock Index and Emerging Islamic Stock Index: Case of Subprime Financial Crises 


\subsection{Volatility Spillover between Dow Jones Standard} Index and Emerging Dow Jones Islamic Index

In order to examine the volatility spillover effect, we employ the GARCH $(1,1)$ model based on the BEKK approach. As mentioned earlier, the diagonal elements in matrix

" $A$ "captures past shock effect, while, the diagonal elements in matrix $B$ measure past volatility effect. From Table 2, the diagonal parameters $\left(\beta_{11}\right.$ and $\left.\beta_{22}\right)$ in matrix $B$ are statistically significant, indicating the presence of strong GARCH effects, namely past volatility affects the conditional variance of all indexes.

Furthermore, the diagonal parameters $\left(a_{11}\right.$ and $\left.a_{22}\right)$ are significant, implying an ARCH effect in all indexes. The off-diagonal elements $\left(a_{12}\right.$ and $\left.a_{21}\right)$ of matrices $A$ and $B$ capture cross-Index effects, such as the shock and volatility spillover effects between the Dow Jones standard Index and Emerging Islamic Dow Jones Index. To demonstrate the role of the financial crisis of 2007 , we classified the data into three periods, pre, in, and post crisis and found the results mentioned above.

The estimation results of the BEKK-GARCH model of the pre-crisis period are reported in Table 1 . We found no evidence of the shock spillover effect between the Dow Jones Standard Index and the emerging Dow Jones Islamic Indexes because coefficients $a_{12}, a_{21}, \beta_{12}$ and $\beta_{21}$ are not significant at $1 \%$ level. This implies what there are no significant effects on the present volatility between all Indexes and that the increase in the Standard Dow Jones Index does not change the volatility of the other emerging Dow Jones Islamic Indexes. This explains that before the financial crisis of 2007, the Islamic financial markets were stable and there was no disruption of Islamic indices.

To half of 2007, mortgage markets underwent a crisis called "subprime crisis". This crisis became to a financial crisis that affected all the financial markets worldwide. This turbulence has affected the standards and Islamic financial markets. The estimation results of the BEKKGARCH model in-crisis period are reported in Table 1. We found the evidence of the shock spillover effect between the Dow Jones Standard Index and the emerging Dow
Jones Islamic Indexes because coefficients $a_{12}, a_{21}, \beta 12$ and $\beta_{21}$ are significant at $1 \%$ level. We noticed that the transmission of volatility is not obvious for all indices, since the result demonstrates that there are no significant factors perhaps because of the resistance of Islamic indexes to financial crises.

We noticed that the crisis has not affected the stability of all Islamic indices concerned. Indeed, we explained the non significance of most of the coefficients by the resistance of Islamic indexes dealing with financial crises. The result shows that the transmission differs from one market to another. We also noticed that the most affected indices are those of Asia such as Malaysia, which show a significance at $1 \%$ level $a_{12}(0.0000001)$ and $\beta_{12}(0.0000000)$. However, the other indices were less affected, Mexico $a_{12}$ (0.2704372) and $\beta_{12}(0.67292081)$, Hungary $a_{12}$ $(0.36387246)$ and $\beta_{12}(0.15190820)$ and Turkey $a_{12}$ (0.56482578).

Regarding the crisis period, we can see that most of the markets regained their stability despite the existence of economic problems in some European countries, such as Spain and Greece, as well as some Arab countries, such as Libya, Syria, Tunisia and Egypt. This stability index explains well the non significance of the coefficients on the average and variance.

There are at least two conclusions drawn from this study. Firstly, the results help investors to choose to invest in less risky and more profitable indices. This can certainly makes them have more precise analysis for the types of appropriate investment risk. Secondly, the result show that the Islamic Index screening process is important not only in eliminating the conventional Index but also in providing less risky investment, which is in line with the nature of Islamic value of small uncertainty.

In the rest of our study, we will look at the transmission of volatility between the indices in question by referring to the DCC-GARCH model of Engle and Kroner (1995). This can be done by looking at the period during which the indices are more volatile. As a consequence, the investors will have important information in the way that they may have a 
portfolio of Islamic actions, which are found to have a lower risk in many countries.

\subsection{Dynamic conditional correlation between Dow Jones Index and Dow Jones Islamic index}

To evaluate the progress of correlations between Dow Jones Standard Index and Emerging Dow Jones Islamic Index over time, figures 1 reports the dynamic conditional correlations between both types of Indexes. The links between Indexes during the periods of financial stress are clearly accentuated.

First, correlations are extremely volatile during the crisis period. For many Indexes, this volatility is especially marked during the subprime period crisis of 2007. In all cases, there is a rise in volatility during and following the crisis. Second, in most cases, the greatest in the correlations occurred in the 2008 financial crisis. Third, for almost all the series, the highest correlations are observed during the crisis, and at the end of the period under study. Overall, the subprime crisis or the 2007-2008 financial crises caused significant changes in the coherence between Dow Jones Standard Index and Emerging Dow Jones Islamic indexes, as well as a higher correlation in volatility. During the periods of stress of Dow Jones Indexes, correlations tend to decline and become negative during the subprime crisis, as it is clarified in the correlation graph. According to the results, two main detections can be heighted: (i) volatility progressed over time, but was quite stable before the 20072008 crisis, and (ii) correlations tend to jump during the crisis, display increased links between Dow Jones Standard Index and Emerging Dow Jones Islamic Indexes.

In general, our results show that the subprime crisis played a key role in developing the relationship between conventional and emerging Islamic Dow Jones Indexes. Indeed, the topmost correlations between both types of indices are usually observed during the financial crisis, representing the phenomenon of stock market financialization.

\section{CONCLUSION}

This paper examines the links between classical Dow Jones Index and the Islamic Dow Jones of six emerging stock markets. We first use the bivariate BEKK-GARCH model of Engle and Kroner (1995) to demonstrate the correlation between these indices. Then, based on the DCC-GARCH, we graphically show if the correlations between the indexes change over time and depend on the situation or bullishbearish on the stock market.

The great discovery can be summarized as follows: in a panel of 6 Islamic Indexes over the period from January 3, 2005 - December 31, 2012, the correlations between the different Emerging Islamic Indexes and Dow Jones Standard Index through time, are highly volatile, particularly during the 2007-2008 financial crises. While the stock market collapse has disentangled the links between the two types of Indexes on the very short run, the greatest correlations are observed during the financial crisis, showing increased links between Standard and Islamic Dow Jones Indexes.

On the whole, our detections show that the subprime crisis has played a key role, in showing the links between the Standard Dow Jones and the Emerging Dow Jones Islamic Indexes, and highlighting the financialization of commodity markets. 


\section{REFERENCES}

Ahlgren, N \& Antell, J. (2009),’Stock Market Linkages and Financial Contagion: A

Cobreaking Analysis," The Quarterly Review of Economics and Finance 50 (2010) $157-166$.

Al-Zoubi and Maghyereh (2007), "The Relative Risk Performance of Islamic Finance: A New Guide To Less Risky Investments," International Journal of Theoretical and Applied Finance, Vol. 10, No. 2, pp. 235-249.

Charles, Amélie, Pop, Adrian and Darné, Olivier (2011), Is the Islamic Finance Model More Resilient than the Conventional Finance Model? Evidence from Sudden Changes in the Volatility of Dow Jones Indexes. International Conference of the French Finance Association (AFFI), May 1113, 2011. Available at SSRN:http://ssrn.com/abstract=183675 1.

Engle, R. and Kroner, K.F. (1995). Multivariate Simultaneous Generalized ARCH. Econometric Theory, Vol.11, N.1, pp.122-150.
Karim, Bakri Abdul, Noor AkilaMohdKassim, and Mohammad Affendy Arip (2010)."The Subprime Crisis and Islamic Stock Markets Integration."International Journal of Islamic and Middle Eastern Finance and Management 3(4) 363-371.

Kumar, K and C Mukhopadhyay (2002): "Equity Market Interlinkages: Transmission of Volatility - A Case of US and India", NSE Working Paper No.16.

Majid, M. Shabri Abd., Ahamed KameelMeera, and MohdAzmi Omar (2007). "Interdependence of ASEAN-5 Stock Markets from the US and Japan."20th Australasian Finance \& Banking Conference.

Rahman, Aisyah Abdu, and Noor ZahirahMohd Sidek (2011)."Spillover Effect of US Sub prime Crisis on ASEAN-5 Stock Markets."Business and Social Science Research Conference. Dubai, UAE: World Business Institute Australia, 334. 
Rizvi, S. Arshad, S. (2012) “Are Islamic Equity Indices a Safer Haven in Times of Crisis? An Empirical Proof Via Investigation of Global Indices Using Multivariate GARCH DCC." International Islamic Capital Market Conference, Indonesia.

Wong W K, A Agarwal and J Du (2005): "Financial Integration for India Stock Market, a Fractional Cointegration Approach", National University of Singapore Working Paper No. WP0501.

Yang, J. and Qiu, W. (2005), “A measure of risk and a decision-making model based on expected utility and entropy," European Journal of Operational Research 164, 792-799. 
FIG 1: Conditional Correlation between DJI \& DJEII

Conditional sorfelation betwean DЛ \&DHII
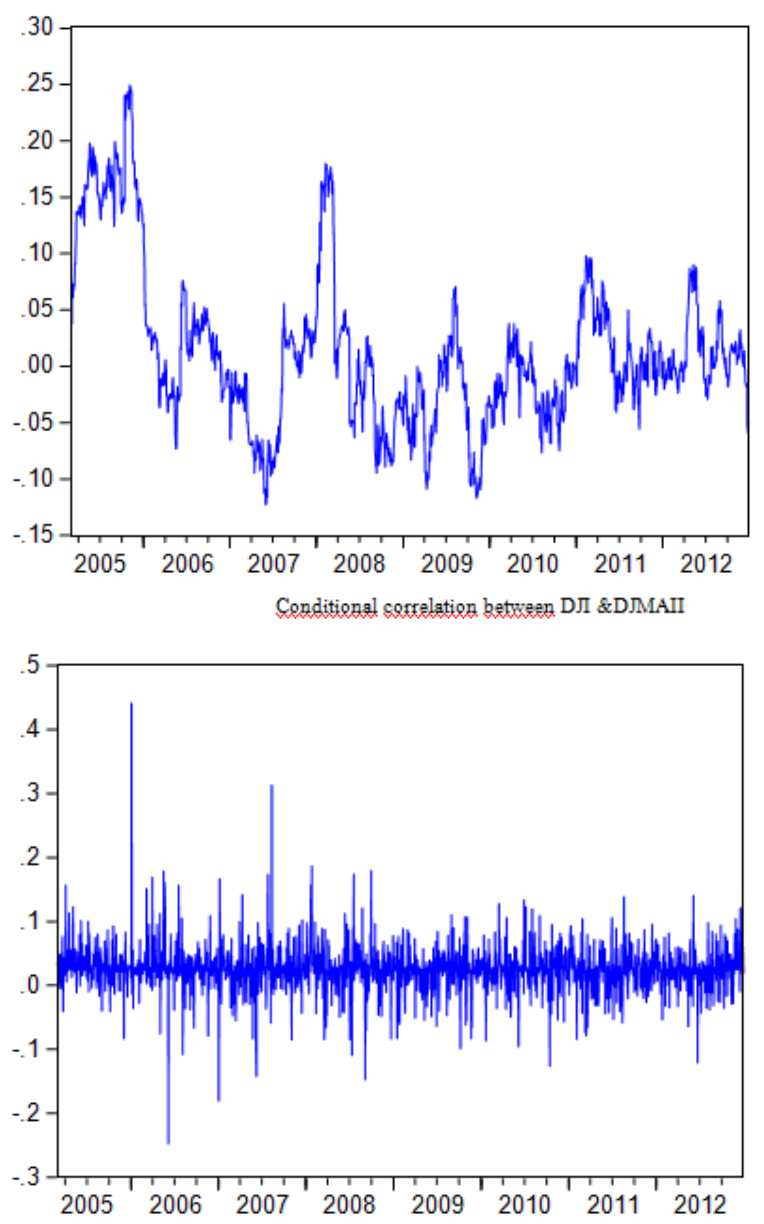

Conditional serfelation between DI \&DMEII

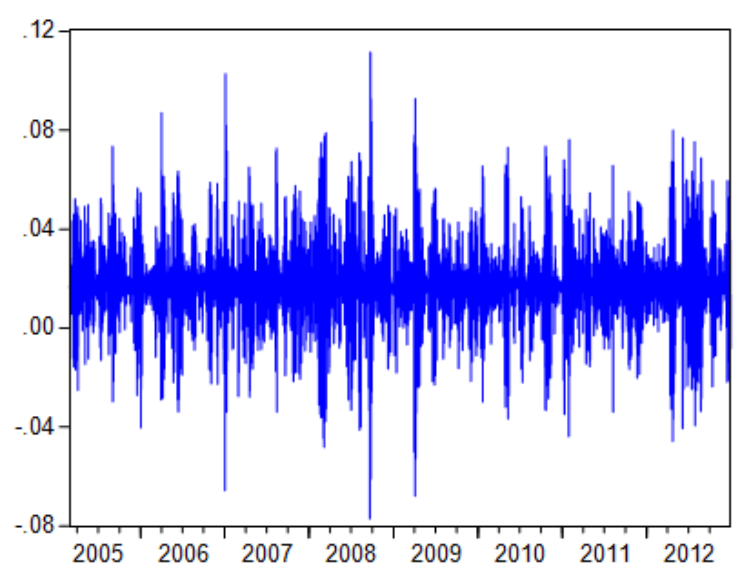

Conditional correlation between DЛ\& DJPEII
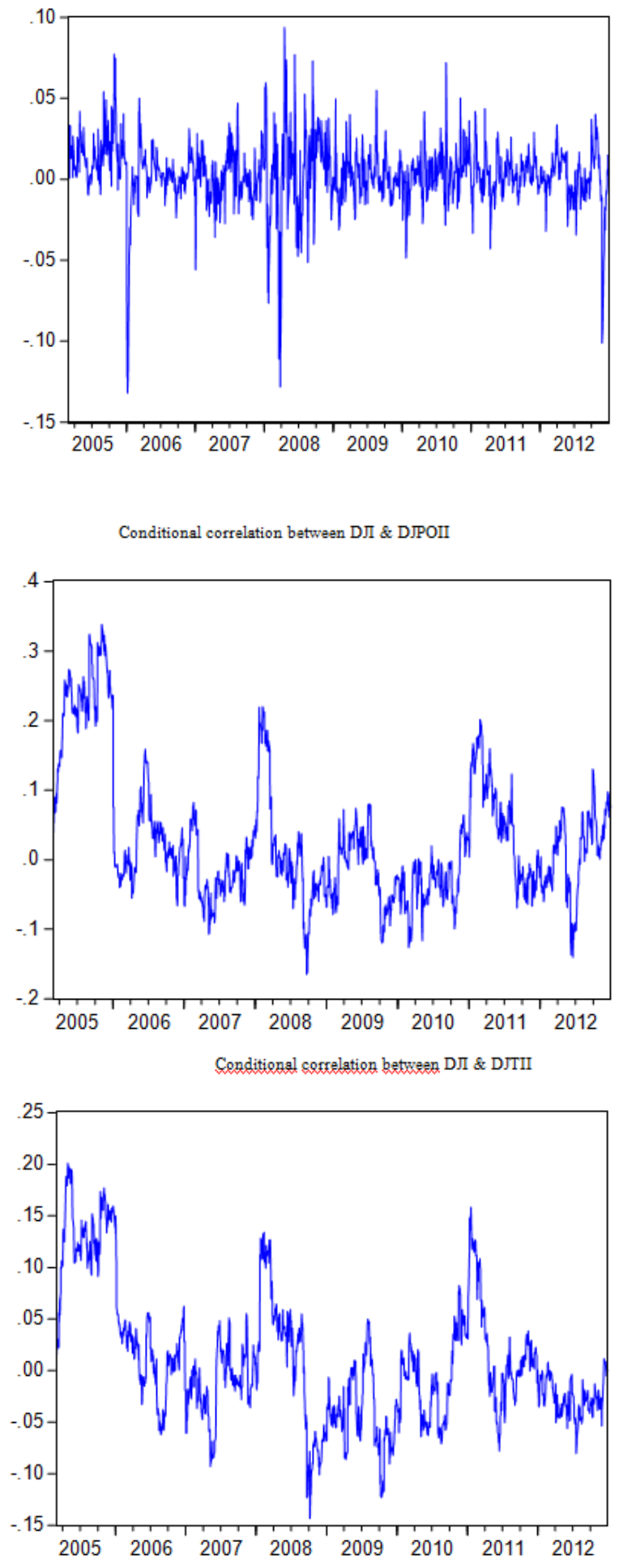